\title{
Long-term remission and recurrence rates after first and second transsphenoidal surgery for Cushing's disease: care reality in the Munich Metropolitan Region
}

\author{
C Dimopoulou 1,2, J Schopohl' ${ }^{2}$ W Rachinger ${ }^{3}$, M Buchfelder ${ }^{4}$, J Honegger ${ }^{5}$, \\ M Reincke ${ }^{2, *}$ and G K Stalla ${ }^{1, *}$ \\ ${ }^{1}$ Department of Endocrinology, Max Planck Institute of Psychiatry, Kraepelinstrasse 2-10, 80804 Munich, Germany, \\ ${ }^{2}$ Medizinische Klinik und Poliklinik IV, Ludwig-Maximilians-University, Munich, Germany, ${ }^{3}$ Department of \\ Neurosurgery, Klinikum Grosshadern, University of Munich, Munich, Germany, ${ }^{4}$ Department of Neurosurgery, \\ University of Erlangen-Nürnberg, Erlangen, Germany and ${ }^{5}$ Department of Neurosurgery, University of Tuebingen, \\ Tuebingen, Germany \\ *(M Reincke and G K Stalla contributed equally to this work)
}

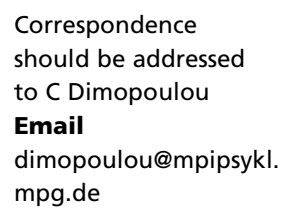

\begin{abstract}
Objective: Transsphenoidal surgery (TSS) presents the treatment of choice for Cushing's disease (CD). Remission and recurrence rates vary dependent on tumor size, extension, adenoma visibility on magnetic resonance imaging, and neurosurgical expertise. Other than published from single-surgeon neurosurgical series so far, we have aimed to describe long-term remission and recurrence rates of $C D$ in a series incorporating different neurosurgeons, trying to reflect care reality in the Munich Metropolitan Region, which is accommodated by three tertiary university and multiple, smaller neurosurgical centers.

Design: We conducted a retrospective analysis of 120 patients who underwent first and 36 patients who underwent second TSS as treatment for CD between 1990 and 2012.

Methods: Patients were divided into three groups according to remission status. Potential risk factors for recurrence, pituitary function, and strategy in persistent disease were assessed.

Results: Three outcome groups were identified according to remission status after first TSS (mean follow-up 79 months): remission, 71\% (85/120), disease persistence, 29\% (35/120), and disease recurrence, 34\% (29/85) (mean time to recurrence 54 months). After second TSS ( $n=36$, mean follow-up 62 months), we documented remission in $42 \%$ (15/36), disease persistence in $58 \%$ (21/36), and disease recurrence in $40 \%$ (6/15) (mean time to recurrence 42 months). Postoperative hypocortisolism after first, though not after second, TSS was associated with a lower risk of suffering disease recurrence (risk $=0.72 ; 95 \% \mathrm{Cl} 0.60-0.88$; exact significance (two-sided) $P=0.035$ ).

Conclusions: Our study shows higher recurrence rates of CD after first TSS than previously reported. Second TSS leads an additional $8 \%$ of the patients to long-term $C D$ remission.
\end{abstract}

\section{Introduction}

Cushing's disease (CD), caused by an adrenocorticotropin (ACTH)-secreting pituitary adenoma, is a rare condition associated with increased morbidity and mortality $(1,2)$.
According to the present treatment algorithm, transsphenoidal surgery (TSS) presents the treatment of choice for CD (3). Dependent on tumor size and extension, adenoma 
visibility on preoperative magnetic resonance imaging (MRI), and neurosurgical expertise, remission rates after first TSS range from 70 to $90 \%(4,5,6,7)$. Remission rates in patients having macroadenomas are lower $(8,9)$. Despite successful first TSS, the 10-year recurrence rates of CD range between 20 and 25\% (mean time to relapse 49 months) (4); microscopic remnants of the corticotroph adenoma are suggested to be involved in $\mathrm{CD}$ persistence or recurrence (10). In that case, further therapeutic options comprise second TSS leading only $50-70 \%$ of patients to remission (11), radiotherapy, medical therapy, and bilateral adrenalectomy.

Main characteristics and outcomes of previous, singlesurgeon studies on remission and recurrence rates after TSS for $\mathrm{CD}$ are presented in Table 1.

The aim of our study was to analyze long-term remission and recurrence rates of CD after first $(n=120)$ and second TSS $(n=36)$ in the Munich Metropolitan Region (3.27 million, population as by ESPON 2007), which is accommodated by three major tertiary university neurosurgical centers and multiple, smaller neurosurgical centers, reflecting care reality in this region. We hypothesized that remission rates might be lower and recurrence rates might be higher in our series incorporating different neurosurgeons, when compared with remission and recurrence rates published from single-surgeon expert neurosurgical series. Moreover, we focused on the role of second TSS in the current therapeutic regimen for CD, attempted a correlation between postoperative hypocortisolism and risk of recurrence and described our therapeutic strategy in patients with persistent disease after TSS.

\section{Subjects and methods}

\section{Patients}

We report on a series of $120 \mathrm{CD}$ patients: 53 treated at the Department of Endocrinology, Max Planck Institute of Psychiatry, Munich and 67 treated at the Medizinische Klinik und Poliklinik IV, Ludwig-Maximilians-University, Munich, both cooperating partners of the Network of Excellence for Neuroendocrine Tumors Munich (NeoExNET). All patients underwent TSS as initial treatment for CD between 1990 and 2012 and had a documented follow-up of at least 6 months. Medical records were analyzed to obtain demographic data, laboratory values, tumor characteristics, comorbidities, previous and current therapy, therapy outcome, pituitary function, and duration of postoperative hypocortisolism. Baseline characteristics of the study population are presented in Table 2.

Table 1 Main characteristics and outcomes of previous, single-surgeon studies on remission and recurrence rates after transsphenoidal surgery for Cushing's disease. All studies included 50 or more patients and were published since 2000.

\begin{tabular}{|c|c|c|}
\hline Study & Year & $\begin{array}{c}\text { Number of } \\
\text { patients }\end{array}$ \\
\hline (22) & 2001 & 61 \\
\hline (36) & 2001 & 300 \\
\hline (32) & 2002 & 89 \\
\hline (20) & 2002 & 53 \\
\hline (37) & 2003 & 174 \\
\hline (38) & 2003 & 147 \\
\hline (39) & 2003 & 78 \\
\hline (17) & 2004 & 289 \\
\hline (40) & 2006 & 100 \\
\hline (41) & 2007 & 103 \\
\hline (14) & 2008 & 215 \\
\hline (5) & 2008 & 426 \\
\hline (42) & 2008 & 167 \\
\hline (6) & 2009 & 261 \\
\hline (7) & 2010 & 620 \\
\hline (31) & 2011 & 331 \\
\hline (34) & 2012 & 80 \\
\hline (43) & 2013 & 131 \\
\hline (2) & 2013 & 346 \\
\hline This study & 2013 & 120 \\
\hline
\end{tabular}

\begin{tabular}{c}
\hline $\begin{array}{c}\text { Follow-up } \\
\text { (in months) }\end{array}$ \\
\hline 88 \\
NA \\
92 \\
72 \\
60 \\
61 \\
86 \\
133 \\
19 \\
72 \\
45 \\
72 \\
40 \\
84 \\
NA \\
132 \\
55 \\
184 \\
76 \\
79
\end{tabular}

Overall remission Overall remission
rate (\% patients)

$\frac{\text { rate }(\% \text { patients) }}{79}$

Recurrence rate

\begin{tabular}{c} 
(\% patients) \\
\hline 15 \\
15 \\
11
\end{tabular}

69

77

82

98

72

82

75

85

86

69

80

92

71

89

72

68

89

71
Time to relapse (mean/ median in months)

NA, not applicable. 
Table 2 Baseline characteristics of the study population.

\begin{tabular}{|c|c|}
\hline & All patients $(n=120)$ \\
\hline \multicolumn{2}{|l|}{ Gender } \\
\hline Females & $96(80 \%)$ \\
\hline Males & $24(20 \%)$ \\
\hline Age (years) (mean (range)) & $50(27-86)$ \\
\hline $\begin{array}{l}\text { Age at first diagnosis (years) } \\
\text { (mean (range)) }\end{array}$ & $41(9-78)$ \\
\hline BMI $\left(\mathrm{kg} / \mathrm{m}^{2}\right)($ mean \pm s.D. $)$ & $28 \pm 7$ \\
\hline \multicolumn{2}{|l|}{$\begin{array}{l}\text { Type of tumor (based on } \\
\text { preoperative MRI) }\end{array}$} \\
\hline Macroadenoma & $32(27 \%)$ \\
\hline Visible microadenoma & $58(48 \%)$ \\
\hline No visible adenoma & $30(25 \%)$ \\
\hline Cavernous sinus invasion (CSI) & $13(11 \%)$ \\
\hline Macroadenoma & $8(7 \%)$ \\
\hline Microadenoma & $5(4 \%)$ \\
\hline \multicolumn{2}{|l|}{ Ethnicities/races } \\
\hline Caucasian & $120(100 \%)$ \\
\hline \multicolumn{2}{|l|}{ Preoperative laboratory values } \\
\hline Serum cortisol 08.00 ( $\mu \mathrm{g} / \mathrm{dl})$ (mean \pm s.D.) & $31 \pm 26$ \\
\hline UFC ( $\mu \mathrm{g} / 24 \mathrm{~h})($ mean \pm s.D. $)$ & $430 \pm 602$ \\
\hline Plasma ACTH (pg/ml) (mean \pm s.D.) & $86 \pm 73$ \\
\hline \multicolumn{2}{|l|}{ Comorbidities } \\
\hline Arterial hypertension & $60(50 \%)$ \\
\hline Diabetes mellitus & $22(18 \%)$ \\
\hline Dyslipidemia & $20(17 \%)$ \\
\hline Osteoporosis & $26(22 \%)$ \\
\hline Depression & $26(22 \%)$ \\
\hline $\begin{array}{l}\text { Mean follow-up for clinical data } \pm \text { s.D. } \\
\text { (months) }\end{array}$ & $79 \pm 67$ \\
\hline
\end{tabular}

\section{Biochemical criteria for CD}

Initial testing for hypercortisolism was performed using one of the following tests: urine free cortisol (UFC; at least two measurements), late-night salivary cortisol (two measurements), or $1 \mathrm{mg}$ overnight dexamethasone suppression test (DST) (low-dose DST, LDDST) (12). Criteria confirming hypercortisolism were UFC greater than the normal range for the assay, serum cortisol $>5 \mu \mathrm{g} / \mathrm{dl}$ after LDDST, and late-night salivary cortisol $>145 \mathrm{ng} / \mathrm{dl}$.
Once the diagnosis of hypercortisolism was established, subtype determination was performed in all patients by the measurement of plasma ACTH, $8 \mathrm{mg}$ overnight DST (high-dose DST, HDDST), and a corticotropin-releasing hormone $(\mathrm{CRH})$ stimulation test $(100 \mu \mathrm{g}$ human CRH i.v.) (13). As a cutoff for diagnosis of CD, we used plasma ACTH values $>20 \mathrm{pg} / \mathrm{ml}$, a $35 \%$ increase in plasma ACTH and a 20\% increase in serum cortisol during the CRH stimulation test and/or a more than 50\% suppression of cortisol during HDDST (13). Additional inferior petrosal sinus sampling (IPSS) was recommended in all cases of no visible adenoma on preoperative MRI $(n=30)$; out of these, 25 patients $(21 \%)$ received IPSS and five patients rejected it. Pituitary origin of hypercortisolism was confirmed in all the patients who received IPSS $(n=25)$.

\section{Preoperative imaging}

Preoperative imaging included thin-section MRI ( $2 \mathrm{~mm}$ ) of the pituitary comprising dynamic sequences. Radiological findings - interpreted both by radiologists and neurosurgeons in all centers - were divided into three groups: i) diagnosis of a clearly visible microadenoma $(<10 \mathrm{~mm})$; ii) diagnosis of a macroadenoma $(\geq 10 \mathrm{~mm})$; and iii) no visible adenoma.

\section{Neurosurgical centers, surgical technique, and histopathological findings}

The Munich Metropolitan Region is accommodated by three major tertiary university referral centers for neurosurgery: Klinikum Grosshadern, Munich (operator W R), University of Erlangen-Nürnberg (operator M B), and University of Tuebingen (operator $\mathrm{J} \mathrm{H}$ ) (number of pituitary surgeries per surgeon/year and total number of pituitary surgeries at center are presented in Table 3).

Table 3 Neurosurgical centers where first and second TSS were performed.

\begin{tabular}{|c|c|c|c|c|}
\hline & $\begin{array}{c}\text { First TSS } \\
(n=120)\end{array}$ & $\begin{array}{l}\text { Second TSS } \\
\quad(n=36)\end{array}$ & $\begin{array}{l}\text { Number of pituitary } \\
\text { surgeries per surgeon/year }\end{array}$ & $\begin{array}{c}\text { Total number of pituitary surgeries at } \\
\text { center (single surgeon) }\end{array}$ \\
\hline $\begin{array}{l}\text { Klinikum Grosshadern, } \\
\text { Munich }\end{array}$ & $46(38 \%)$ & $8(22 \%)$ & $80-90$ & 850 \\
\hline $\begin{array}{l}\text { University of Erlangen- } \\
\text { Nürnberg }\end{array}$ & $19(16 \%)$ & $10(28 \%)$ & $250-300^{a}$ & 2000 \\
\hline University of Tuebingen & $12(10 \%)$ & $2(6 \%)$ & 100 & 1100 \\
\hline Other centers & $43(36 \%)$ & $16(44 \%)$ & & \\
\hline
\end{tabular}

${ }^{a}$ Number of pituitary surgeries per surgeon/year in University of Erlangen-Nürnberg since 2005. 
The majority of the study population underwent TSS in one of the above-mentioned neurosurgical centers (first TSS: $77 / 120,64 \%$; second TSS: $20 / 36,56 \%)$. Forty-three of $120(36 \%)$ and 16 of 36 patients (44\%) underwent first and second TSS, respectively, in a smaller neurosurgical center (Table 3).

All patients underwent surgery by microscopic transsphenoidal approach.

Pathology reports of the surgically excised specimens were available for the patients operated upon in a tertiary university referral center. Comparable with the literature (14), an ACTH-staining adenoma was confirmed in 75.3 and $75 \%$ of patients after first and second TSS respectively. In the remaining cases, no abnormality (= normal pituitary tissue) could be detected.

\section{Postoperative biochemical evaluation}

Postoperatively, patients were administered hydrocortisone only after adrenal insufficiency was confirmed (serum cortisol $<5 \mu \mathrm{g} / \mathrm{dl}$ ). The first outpatient postoperative evaluation was performed 4-6 weeks after TSS. Patients were seen in clinic, off hydrocortisone replacement for 2 days, and serum cortisol levels were measured. In case of postoperative hypocortisolism (serum cortisol $<5 \mu \mathrm{g} / \mathrm{dl}$ ), hydrocortisone supplementation was resumed. Duration of postoperative hypocortisolism was confirmed by repeated serum cortisol measurements. Other patients underwent a one-sample UFC or a LDDST to establish remission status. Remission was defined as 24-h UFC values below or within normal range for the assay used or serum cortisol below $5 \mu \mathrm{g} / \mathrm{dl}$ during a LDDST. Persistent disease or disease recurrence after remission was defined as an elevated 24-h UFC above the upper limit of the range for the assay used or as a lack of cortisol suppression below $5 \mu \mathrm{g} / \mathrm{dl}$ during LDDST with clinical symptoms consistent with CD. Perioperative management including timing of hydrocortisone initiation postoperatively and hydrocortisone withdrawal 2 days before assessment of hypocortisolism was similar over all participating centers.

Evaluation of further pituitary axes comprised basal fasting measurements of insulin-like growth factor 1 (IGF1), thyrotropin (TSH), free thyroxine, total triiodothyronine, luteinizing hormone (LH), folliclestimulating hormone (FSH), prolactin, and testosterone (in men) or estradiol (in women) in all patients (15). In case of low serum IGF1, diagnosis of growth hormone deficiency was established by dynamic testing via the insulin tolerance test (ITT) or the growth hormonereleasing hormone-arginine test (16).
Final follow-up was defined as the last patient's contact with the endocrinological referral center including patients after first and/or second TSS, radiation therapy, bilateral adrenalectomy, and medical therapy.

\section{Statistical analysis}

Statistical analysis was performed using PASW Statistics Version 18 for Windows. Data for descriptive statistics including mean age, mean follow-up time, and mean time to recurrence are presented as mean \pm s.D. (range). KaplanMeier analysis for recurrence was performed using the product-limit method. Differences in recurrence rates between patient groups (positive preoperative MRI vs negative MRI; patients who underwent surgery in different university referral centers, patients with postoperative hypocortisolism vs patients with postoperative eucortisolism) were assessed using $\chi^{2}$ analysis. A $P$ value of $<0.05$ was considered statistically significant.

\section{Results}

\section{First TSS}

Remission rates $\downarrow$ The overall remission rate following primary surgery was $71 \%(n=120)$. In the microadenoma group ( $n=58)$, a remission rate of $79 \%$ was achieved; in the macroadenoma group $(n=32)$, remission rate after first TSS was $69 \%$. In cases of no visible adenoma $(n=30)$, remission rate was $57 \%$ (Table 4 ).

Recurrence rates $>$ Mean follow-up after first TSS was $79 \pm 67$ (range 252) months. Overall recurrence rate after successful first TSS was 34\% (22\% of patients with microadenoma, $59 \%$ of patients with macroadenoma, and $35 \%$ of patients with no visible adenoma; $P=0.007$ ). The time to recurrence after first TSS ranged from 5 to 205 months, with a mean of $54 \pm 54$ months.

\section{Second TSS}

According to the current algorithm for the management of CD (4), second TSS was considered in all cases of persistent or recurrent CD after first TSS $(n=64)$. Reasons for not performing second TSS $(n=28)$ included patients with ACTH-secreting macroadenomas with tumor invasion into the cavernous sinus or sphenoid $(n=8)$, who might not benefit from a second TSS, patients' unwillingness to undergo second TSS $(n=12)$, and other contraindications to surgery $(n=8)$. 
Table 4 Remission rates, disease persistence, recurrence rates, and mean time to recurrence after first and second TSS and at final follow-up according to preoperative MRI. Comparisons between groups were calculated using $\chi^{2}$ analysis.

\begin{tabular}{l}
\hline \\
\hline First TSS \\
Remission \\
Disease persistence \\
Recurrence \\
Mean time to recurrence \\
\pm s.D. (months) \\
Second TSS \\
Remission \\
Disease persistence \\
Recurrence \\
Mean time to recurrence \\
\pm s.D. (months) \\
Final follow-up \\
Remission \\
Disease persistence
\end{tabular}

\begin{tabular}{c}
\hline All patients \\
\hline$n=120$ \\
$85(71 \%)$ \\
$35(29 \%)$ \\
$29 / 85(34 \%)$ \\
$54 \pm 54$ \\
$n=36$ \\
$15(42 \%)$ \\
$21(58 \%)$ \\
$6 / 15(40 \%)$ \\
$27 \pm 29$ \\
$n=120$ \\
$110(92 \%)$ \\
$10(8 \%)$ \\
\end{tabular}

\begin{tabular}{c}
\hline Macroadenoma \\
\hline$n=32$ \\
$22(69 \%)$ \\
$10(31 \%)$ \\
$13 / 22(59 \%)$ \\
$41 \pm 35$ \\
$n=14$ \\
$4(29 \%)$ \\
$10(71 \%)$ \\
$3 / 4(75 \%)$ \\
$35 \pm 36$ \\
$n=32$ \\
$24(75 \%)$ \\
$8(25 \%)$ \\
\hline
\end{tabular}

\begin{tabular}{c}
\hline Microadenoma \\
\hline$n=58$ \\
$46(79 \%)$ \\
$12(21 \%)$ \\
$10 / 46(22 \%)$ \\
$44 \pm 30$ \\
$n=14$ \\
$5(36 \%)$ \\
$9(64 \%)$ \\
$2 / 5(40 \%)$ \\
$15 \pm 16$ \\
$n=58$ \\
$56(97 \%)$ \\
$2(3 \%)$ \\
\hline
\end{tabular}

\begin{tabular}{c}
\hline No visible adenoma \\
\hline$n=30$ \\
$17(57 \%)$ \\
$13(43 \%)$ \\
$6 / 17(35 \%)$ \\
$102 \pm 96$ \\
$n=8$ \\
$6(75 \%)$ \\
$2(25 \%)$ \\
$1 / 6(17 \%)$ \\
$120 \pm 0$ \\
$n=30$ \\
$30(100 \%)$ \\
$0(0 \%)$
\end{tabular}

\begin{tabular}{c}
\hline P value \\
\hline 0.035 \\
0.082 \\
0.007 \\
0.075 \\
\\
\\
0.124 \\
0.065 \\
0.611 \\
0.522 \\
\\
0.000 \\
0.000
\end{tabular}

Remission rates $>$ Thirty-six of $120 \mathrm{CD}$ patients (30\%) underwent second TSS. Second TSS was carried out by the same surgeon, in the same neurosurgical center where first TSS took place in 64\% (23/36), suggesting patients' satisfaction. After second TSS, overall remission rate of CD was $42 \%$ (36\% of patients with microadenoma, $29 \%$ of patients with macroadenoma, and $75 \%$ of patients with no visible adenoma).

Recurrence rates $>$ Mean follow-up after second TSS was $62 \pm 54$ (range 187) months. Overall recurrence rate after successful second TSS was $40 \%$ (40\% of patients with microadenoma, $75 \%$ of patients with macroadenoma, and $17 \%$ of patients with no visible adenoma). The time to recurrence after second TSS was shorter (mean $27 \pm 29$, range 3-76 months). Kaplan-Meier analysis of CD recurrence after successful first and/or second TSS is shown in Fig. 1.

\section{No adenoma visibility on preoperative MRI}

In this analysis, 30 patients with no visible tumor on preoperative MRI underwent first TSS; a pituitary adenoma could be detected during surgery in $16 / 30$ cases (53\%). In the remaining cases $(n=14)$, a systematic dissection of the pituitary gland was performed; only one patient received total hypophysectomy. Regarding second TSS, of the eight patients with no visible tumor preoperatively, a pituitary adenoma was visualised during surgery in $2 / 8$ cases $(25 \%)$. A systematic dissection of the pituitary gland was performed in the remaining six patients; one patient received a hemi-hypophysectomy.
Hemi-hypophysectomy was performed on the side on which an adenoma was most likely suspected or on the side with a suspicious area on MRI. If IPSS was available, then hemi-hypophysectomy would be performed on the side with greater ACTH values. Remission rates after first and second TSS when definite tumor was not found during surgery were 50 and $100 \%$ respectively.

Role of neurosurgical center, cavernous sinus invasion, and IPSS

Analysis of outcomes at each participating center showed that remission and recurrence rates after first and after second TSS were not significantly different (Table 5). There were no significant differences in remission and recurrence rates between tumors with and without cavernous sinus invasion (CSI) neither after first ( $P=0.237$ and $P=0.846$ respectively) nor after second TSS ( $P=0.335$ and $P=0.306$ respectively).

There were no significant differences in remission and recurrence rates after first and second TSS and at the final follow-up between the group of patients who received IPSS $(n=25)$ and those who did not.

\section{Postoperative hypocortisolism and risk of recurrence}

Diagnosis of postoperative hypocortisolism was based in all patients on biochemical testing while in hospital (serum cortisol $<5 \mu \mathrm{g} / \mathrm{dl}$ ).

First TSS • After first TSS, 65/120 CD patients (54\%) were presented with postoperative hypocortisolism $(64 \%$ in the 


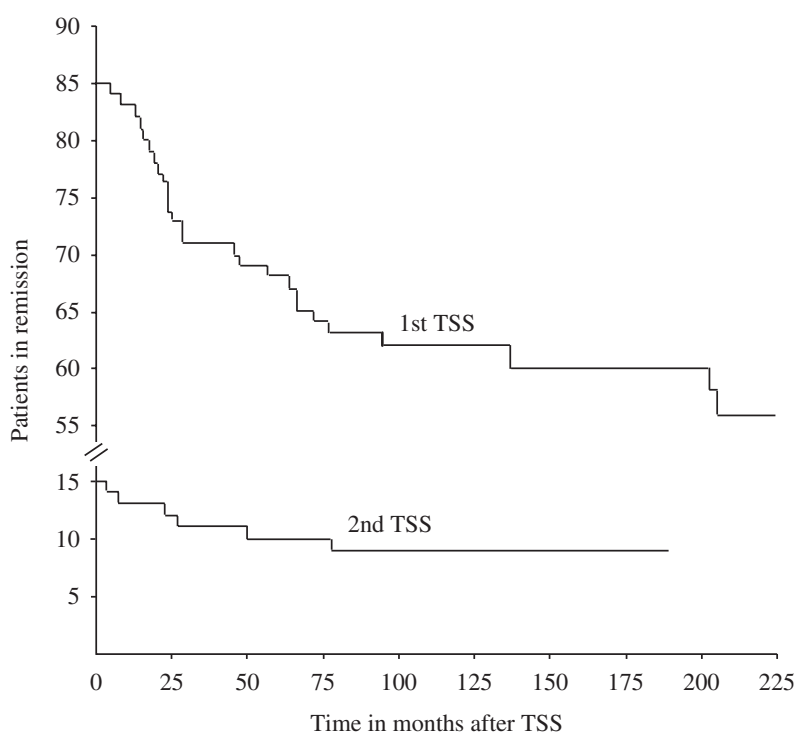

\section{Figure 1}

Kaplan-Meier curve showing freedom from recurrence of Cushing's disease in patients after successful first and/or second TSS.

microadenoma group, $47 \%$ in the macroadenoma group, and $43 \%$ in the group of no visible adenoma) (mean duration $45 \pm 60$, range 252 months). Patients who had postoperative hypocortisolism after first TSS were 0.7 times less likely to suffer disease recurrence than patients with postoperative eucortisolism (risk $=0.72$; 95\% CI 0.60-0.88; exact significance (two-sided) $P=0.035)$. Longer duration of postoperative hypocortisolism did not prevent CD recurrence $(48 \pm 64$ vs $32 \pm 22$ months; $P=0.186)$.

Second TSS - After second TSS, overall frequency of postoperative hypocortisolism was 33\% (12/36 patients)
(36\% in the microadenoma group, $29 \%$ in the macroadenoma group, and $63 \%$ in the group of no visible adenoma) (mean duration $15 \pm 16$, range 56 months). Neither the presence of postoperative hypocortisolism after second TSS (risk $=0.83$; 95\% CI 0.25-2.73; exact significance (two-sided) $P=1.000$ ), nor its longer duration $(17 \pm 17$ vs 5 months; $P=0.55)$ prevented patients from disease recurrence.

\section{Strategy in patients with persistent disease after first and/or after second TSS}

Strategy in patients with persistent disease after first and/or after second TSS is shown in Fig. 2a and b. Overall incidence of Nelson's syndrome in our series was $23 \%$ (five of 22 bilaterally adrenalectomized patients).

\section{Final follow-up}

Remission rates $\downarrow$ Of the $120 \mathrm{CD}$ patients included in this analysis, 92\% were in remission at final follow-up (100\% in the group of no visible adenoma, $97 \%$ in the microadenoma, and $75 \%$ in the macroadenoma group). Overall, $8 \%$ of the CD patients suffered from disease persistence at final follow-up (Table 4). Nine patients were lost to follow-up ( $n=8$ after first TSS, $n=1$ after second TSS).

Pituitary function $~$ At final follow-up, 81 of $120(68 \%)$ patients presented with deficiency of at least one pituitary hormone, with ACTH being affected in the majority of cases with 51\% (isolated ACTH deficiency in 29\%). Frequencies of LH/FSH, TSH, and GH deficiencies accounted for 29, 22, and 22\% respectively. Posterior pituitary deficiency was less frequent with $8 \%$.

Table 5 Remission rates, disease persistence, and recurrence rates after first and second TSS according to neurosurgical center. Comparisons between groups were calculated using $\chi^{2}$ analysis.

\begin{tabular}{|c|c|c|}
\hline & All patients & $\begin{array}{c}\text { Klinikum Grosshadern } \\
\text { Munich }\end{array}$ \\
\hline First TSS & $n=77$ & $n=46$ \\
\hline Remission & $56(72 \%)$ & $35(76 \%)$ \\
\hline Disease persistence & $21(28 \%)$ & $11(24 \%)$ \\
\hline Recurrence & $13 / 56(23 \%)$ & $12 / 35(34 \%)$ \\
\hline Second TSS & $n=20$ & $n=8$ \\
\hline Remission & $8(40 \%)$ & $3(38 \%)$ \\
\hline Disease persistence & $12(60 \%)$ & $5(62 \%)$ \\
\hline Recurrence & $2 / 8(25 \%)$ & $1 / 3(33 \%)$ \\
\hline
\end{tabular}

\begin{tabular}{|c|}
\hline $\begin{array}{l}\text { University of Erlangen- } \\
\text { Nürnberg }\end{array}$ \\
\hline$n=19$ \\
\hline $12(63 \%)$ \\
\hline $7(37 \%)$ \\
\hline $1 / 12(8 \%)$ \\
\hline$n=10$ \\
\hline $4(40 \%)$ \\
\hline $6(60 \%)$ \\
\hline $1 / 4(25 \%)$ \\
\hline
\end{tabular}

\begin{tabular}{ccc}
\hline $\begin{array}{c}\text { University of } \\
\text { Tuebingen }\end{array}$ & & P value \\
\cline { 1 - 2 }$n=12$ & & \\
$9(75 \%)$ & & 0.409 \\
$3(25 \%)$ & & 0.557 \\
$0 / 9(0 \%)$ & & 0.061 \\
$n=2$ & & \\
$1(50 \%)$ & & 0.949 \\
$1(50 \%)$ & & 0.949 \\
$0 / 1(0 \%)$ & & 0.870
\end{tabular}

www.eje-online.org 

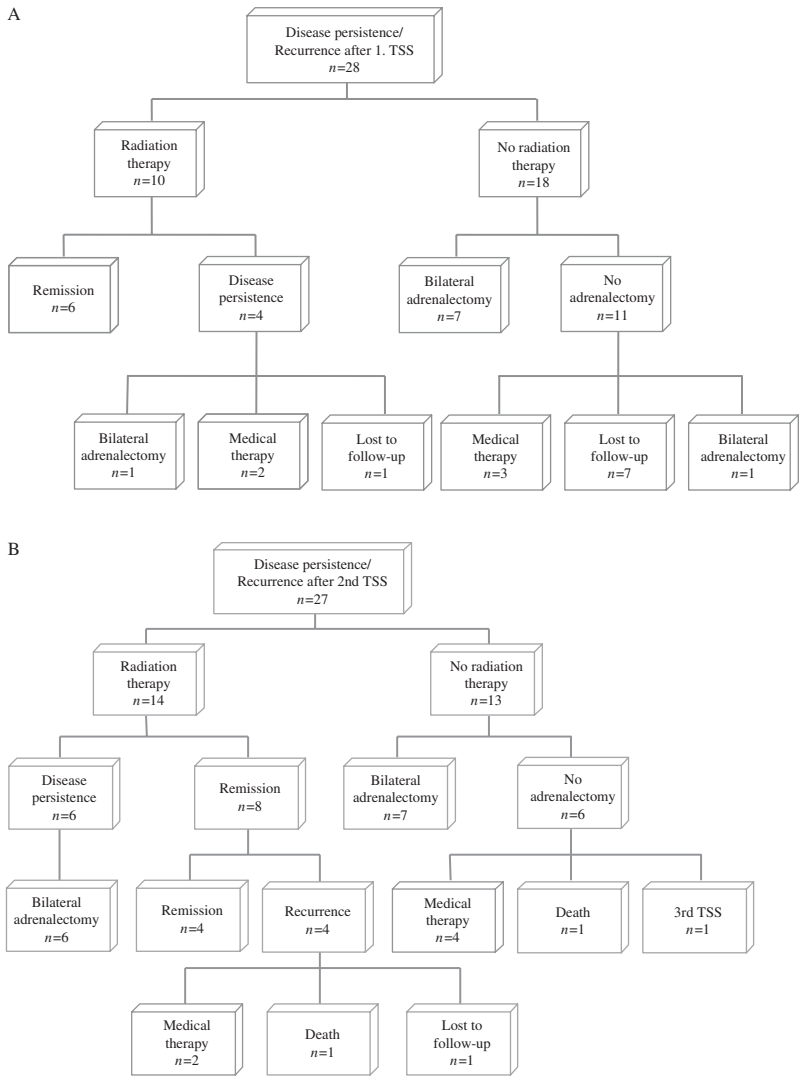

Figure 2

Strategy in patients with persistent disease after first (A) and second TSS (B).

\section{Discussion}

Here, we report on long-term remission and recurrence rates of CD after first and second TSS in the Munich Metropolitan Region, accommodated by three major tertiary and multiple, smaller neurosurgical centers incorporating different neurosurgeons. Our hypothesis was that remission rates might be lower and recurrence rates might be higher in our series compared with published single-surgeon neurosurgical series so far.

\section{First TSS}

Remission rates following TSS for CD vary between 69 and 98\%, as reported since 1995 (mean follow-up 65 months) (4). Several factors including tumor size and extension, adenoma visibility on preoperative MRI, during the operation or in pathology as well as neurosurgical expertise have been suggested to influence pituitary surgery outcome $(8,17,18,19,20,21,22,23)$. Here, we report an overall remission rate of $71 \%$ after first
TSS comparing favorably with the literature, against our study hypothesis.

Remission rates in macroadenomas are reported to be lower, possibly mediated by CSI and maximum tumor diameter $(8,9,24)$. Our results were again in accordance with published series, as patients with macroadenomas experienced after first TSS lower remission rates compared with those with microadenomas (69 vs 79\%). Of course, we have to concede that our cohort harbored a high prevalence of macroadenomas (27\%) when compared with other series $(20,21,25)$; this might be due to the fact that our endocrinology departments serve as referral centers for difficult, complicated cases.

Lack of consensus regarding remission criteria of $\mathrm{CD}$ has led to a broad range of recurrence rates reported (25). A comprehensive review of large clinical studies reveals a recurrence rate of $20-25 \% 10$ years after surgery (4). It is well established that the longer the period of follow-up, the higher the incidence of recurrence (short-term recurrence rates $0-13 \%$, long-term recurrence rates of $5-27 \%)(26,27,28,29)$. In our study, we documented an overall recurrence rate of CD of $34 \%$ after first TSS, which falls at the higher end of the published range so far, supporting our study hypothesis. This might be partially attributable to the high proportion of macroadenomas in our series and to our long follow-up period in excess of 6 years.

\section{Second TSS}

Second TSS should be considered in patients with refractory or recurrent $\mathrm{CD}$. In the literature, remission rates after second TSS are lower than after first TSS, leading only $50-70 \%$ of patients to remission $(11,30)$. In our series, about one-third of the patients received second TSS, leading to a low remission rate of $42 \%$ and confirming the study hypothesis. We have to take into account that here we report not on a single-, but on a multiple-surgeon series involving different neurosurgical skills and reflecting care reality in the Munich Metropolitan Region. Besides, our series harbored one-quarter of macroadenoma patients, our follow-up period was long ( $>5$ years), and our departments serve as referral centers for complicated cases, all factors of potential negative impact on surgical outcome (3).

Interestingly, after second TSS: i) there were no significant differences in remission rates between patients with macroadenomas compared with those with microadenomas (29 vs $36 \%$; $P=0.124$ ); ii) unlike a number of studies published so far $(20,21)$, patients with no visible 
tumor on preoperative MRI seemed to benefit from the more radical procedure, e.g. hemi-hypophysectomy performed at second TSS showing a paradox high remission rate of $75 \%$; iii) overall CD recurrence rate after second TSS was similar to that after first TSS (40 vs 34\%), recurrence occurred though sooner (42 vs 54 months); and iv) total long-term CD remission after second TSS was $54.2 \%$ (65/120 patients), meaning that performance of second TSS led an additional 9/120 patients to disease remission (long-term CD remission after first TSS 46.7\%, $56 / 120$ patients).

Although CSI has been reported in the literature to be the most important unfavorable preoperative factor affecting operative results in $\mathrm{CD}$, in our series, we could not detect any significant differences in remission and recurrence rates between tumors with and without CSI neither after first nor after second TSS. As we do not question the significance of CSI regarding surgical results, we rather believe that this finding might be explained by our small sample size with CSI (11\%).

\section{Final follow-up}

In our series, overall remission rate of $92 \%$ at final followup compared favorably with the literature, against our study hypothesis. Of course, we have to take into account that final follow-up in our series was defined as the last patient contact with the endocrinological referral center, including patients after first and/or second TSS, radiation therapy, bilateral adrenalectomy, and medical therapy. Nine patients were lost to final follow-up.

\section{Postoperative hypocortisolism and risk of recurrence}

Factors that have been associated with low risk of CD recurrence comprise undetectable or low serum level of cortisol in the early morning, low plasma levels of ACTH, and prolonged ( $>1$ year) requirement for glucocorticoid replacement after pituitary surgery and have been thoroughly discussed in the literature (31). Patil et al (14) demonstrated that patients who had postoperative serum cortisol of $>2 \mu \mathrm{g} / \mathrm{dl}$ were 2.5 times more likely to have a recurrence than patients with a serum cortisol of $\leq 2 \mu \mathrm{g} / \mathrm{dl}$ within 72-h after surgery; however, undetectable postoperative cortisol does not always predict long-term remission of CD (32). In our series, presence of postoperative hypocortisolism after first, though not after second, TSS was associated with a lower risk of CD recurrence; duration of postoperative hypocortisolism did not seem to prevent from disease recurrence.

\section{Strategy in patients with persistent disease after second TSS}

Alternative second line therapies for CD comprise radiotherapy, medical therapy, and bilateral adrenalectomy. In our series, second line therapies for CD led 17/27 of active patients to remission; management of therapy-refractory CD in the remaining 10/27 patients might be challenging, incorporating new medical therapies with improved efficacy. Incidence of Nelson's syndrome in our series (23\%) was comparable with published rates in the literature (23-47\%) (33).

\section{Pituitary function}

In our series, frequencies of hypopituitarism of any degree (68\%), ACTH (51\%) (isolated ACTH deficiency 29\%), and LH/FSH deficiencies (29\%) at final follow-up were compared favorably with those reported in previous large studies $(34,35)$. Interestingly, our rates of $\mathrm{TSH}$ (22\%) and $\mathrm{GH}(22 \%)$ deficiencies are rather lower than those described so far $(20,34,35)$, possibly in part mediated by longer follow-up time accompanied by normal thyrotropic or somatotropic axis function recovery.

\section{Conclusion}

In our series incorporating different neurosurgeons, remission rates after first TSS were comparable with available literature, whereas recurrence rates both after first and second TSS fell at the higher end of the published single-surgeon series so far, supporting our study hypothesis. Second TSS leads an additional $8 \%$ of the patients to long-term CD remission. The presence of postoperative hypocortisolism after first TSS, though not its duration, was associated with a lower risk of CD recurrence. Hypopituitarism of any degree persisted in a subset of patients at final follow-up.

In summary, our results confirm the necessity of longterm, lifelong follow-up in patients with initially successfully treated CD, enlightening the role of second TSS in the current treatment algorithm and reflecting long-term care reality in the Munich Metropolitan Region from the endocrinologist's point of view.

\section{Declaration of interest}

C Dimopoulou received lecture fees from Pfizer Pharma GmbH and Novartis Pharma GmbH. J Schopohl received lecture fees from Pfizer Pharma GmbH, Ipsen International GmbH and Novartis Pharma GmbH. W Rachinger has 
nothing to disclose. M Buchfelder received travel grants and fees for invited lectures from Pfizer Pharma GmbH. J Honegger received lecture fees from Pfizer Pharma GmbH and Novartis Pharma GmbH. M Reincke received lecture fees from Pfizer Pharma $\mathrm{GmbH}$, Ipsen International $\mathrm{GmbH}$, and Novartis Pharma GmbH. In addition, M Reincke received financial support from Novartis Pharma GmbH for a clinical trial. G K Stalla received lecture fees from Pfizer Pharma GmbH, Novo Nordisk Pharma GmbH, Ipsen International $\mathrm{GmbH}$, and Novartis Pharma $\mathrm{GmbH}$.

\section{Funding}

NeoExNET (Network of Excellence for Neuroendocrine Tumors in Munich) is a national database for the evaluation of diagnostics, treatment and outcome in neuroendocrine tumors. NeoExNET is supported by the German Federal Ministry of Education and Research (BMBF; m4 Cluster, 16EX1221J, 01EX1020E) and by an unrestricted educational grant of Novartis Pharma $\mathrm{GmbH}$, Nürnberg, Germany. Members of the NeoExNET - Study group include: Principal investigator: G K Stalla (Max Planck Institute of Psychiatry, Munich). Steering Committee: Felix Beuschlein (Ludwig Maximilian University, Munich), Christoph Auernhammer (Ludwig Maximilian University, Munich), Klaus A Kuhn (Technische Universität München, Munich). This project was partly funded by an Else Kröner-Fresenius grant (2012_A103).

\section{Acknowledgements}

The authors thank Caroline Sievers and Marcus Ising for valuable statistical advice, Marily Theodoropoulou for help with artwork, and Stefanie Held, Ferengis Knerr, Sylvia Lang, Anne Mickisch, and Andrea Osswald for helping to process the patient data.

\section{References}

1 Clayton RN, Raskauskiene D, Reulen RC \& Jones PW. Mortality and morbidity in Cushing's disease over 50 years in Stoke-on-Trent, UK: audit and meta-analysis of literature. Journal of Clinical Endocrinology and Metabolism 201196 632-642. (doi:10.1210/jc.2010-1942)

2 Lambert JK, Goldberg L, Fayngold S, Kostadinov J, Post KD \& Geer EB. Predictors of mortality and long-term outcomes in treated Cushing's disease: a study of 346 patients. Journal of Clinical Endocrinology and Metabolism 201398 1022-1030. (doi:10.1210/jc.2012-2893)

3 Biller BM, Grossman AB, Stewart PM, Melmed S, Bertagna X, Bertherat J, Buchfelder M, Colao A, Hermus AR, Hofland LJ et al. Treatment of adrenocorticotropin-dependent Cushing's syndrome: a consensus statement. Journal of Clinical Endocrinology and Metabolism 200893 2454-2462. (doi:10.1210/jc.2007-2734)

4 Tritos NA, Biller BM \& Swearingen B. Management of Cushing disease. Nature Reviews. Endocrinology 20117 279-289. (doi:10.1038/nrendo. 2011.12)

5 Hofmann BM, Hlavac M, Martinez R, Buchfelder M, Muller OA \& Fahlbusch R. Long-term results after microsurgery for Cushing disease: experience with 426 primary operations over 35 years. Journal of Neurosurgery 2008108 9-18. (doi:10.3171/JNS/2008/108/01/0009)

6 Jagannathan J, Smith R, DeVroom HL, Vortmeyer AO, Stratakis CA, Nieman LK \& Oldfield EH. Outcome of using the histological pseudocapsule as a surgical capsule in Cushing disease. Journal of Neurosurgery 2009 111 531-539. (doi:10.3171/2008.8.JNS08339)

7 Valassi E, Biller BM, Swearingen B, Pecori Giraldi F, Losa M, Mortini P, Hayden D, Cavagnini F \& Klibanski A. Delayed remission after transsphenoidal surgery in patients with Cushing's disease. Journal of Clinical Endocrinology and Metabolism 2010 95 601-610. (doi:10.1210/jc. 2009-1672)
8 Swearingen B, Biller BM, Barker FG II, Katznelson L, Grinspoon S, Klibanski A \& Zervas NT. Long-term mortality after transsphenoidal surgery for Cushing disease. Annals of Internal Medicine 1999130 821-824. (doi:10.7326/0003-4819-130-10-199905180-00015)

9 Shimon I, Ram Z, Cohen ZR \& Hadani M. Transsphenoidal surgery for Cushing's disease: endocrinological follow-up monitoring of 82 patients. Neurosurgery 200251 57-61 discussion 61-62. (doi:10.1097/ 00006123-200207000-00008)

10 Dickerman RD \& Oldfield EH. Basis of persistent and recurrent Cushing disease: an analysis of findings at repeated pituitary surgery. Journal of Neurosurgery 200297 1343-1349. (doi:10.3171/jns.2002.97.6.1343)

11 Ram Z, Nieman LK, Cutler GB Jr, Chrousos GP, Doppman JL \& Oldfield EH. Early repeat surgery for persistent Cushing's disease. Journal of Neurosurgery 199480 37-45. (doi:10.3171/jns.1994.80.1. 0037)

12 Nieman LK, Biller BM, Findling JW, Newell-Price J, Savage MO, Stewart PM \& Montori VM. The diagnosis of Cushing's syndrome: an Endocrine Society Clinical Practice Guideline. Journal of Clinical Endocrinology and Metabolism 200893 1526-1540. (doi:10.1210/ jc.2008-0125)

13 Arnaldi G, Angeli A, Atkinson AB, Bertagna X, Cavagnini F, Chrousos GP, Fava GA, Findling JW, Gaillard RC, Grossman AB et al. Diagnosis and complications of Cushing's syndrome: a consensus statement. Journal of Clinical Endocrinology and Metabolism $2003 \mathbf{8 8}$ 5593-5602. (doi:10.1210/jc.2003-030871)

14 Patil CG, Prevedello DM, Lad SP, Vance ML, Thorner MO, Katznelson L \& Laws ER Jr. Late recurrences of Cushing's disease after initial successful transsphenoidal surgery. Journal of Clinical Endocrinology and Metabolism 200893 358-362. (doi:10.1210/jc.2007-2013)

15 Schneider HJ, Aimaretti G, Kreitschmann-Andermahr I, Stalla GK \& Ghigo E. Hypopituitarism. Lancet 2007369 1461-1470. (doi:10.1016/ S0140-6736(07)60673-4)

16 Molitch ME, Clemmons DR, Malozowski S, Merriam GR \& Vance ML. Evaluation and treatment of adult growth hormone deficiency: an Endocrine Society clinical practice guideline. Journal of Clinical Endocrinology and Metabolism 201196 1587-1609. (doi:10.1210/ jc.2011-0179)

17 Hammer GD, Tyrrell JB, Lamborn KR, Applebury CB, Hannegan ET, Bell S, Rahl R, Lu A \& Wilson CB. Transsphenoidal microsurgery for Cushing's disease: initial outcome and long-term results. Journal of Clinical Endocrinology and Metabolism 200489 6348-6357. (doi:10.1210/ jc.2003-032180)

18 Barker FG II, Klibanski A \& Swearingen B. Transsphenoidal surgery for pituitary tumors in the United States, 1996-2000: mortality, morbidity, and the effects of hospital and surgeon volume. Journal of Clinical Endocrinology and Metabolism 200388 4709-4719. (doi:10.1210/jc. 2003-030461)

19 Invitti C, Pecori Giraldi F, de Martin M \& Cavagnini F. Diagnosis and management of Cushing's syndrome: results of an Italian multicentre study. Study Group of the Italian Society of Endocrinology on the Pathophysiology of the Hypothalamic-Pituitary-Adrenal Axis. Journal of Clinical Endocrinology and Metabolism 199984 440-448. (doi:10.1210/jc.84.2.440)

20 Rees DA, Hanna FW, Davies JS, Mills RG, Vafidis J \& Scanlon MF. Long-term follow-up results of transsphenoidal surgery for Cushing's disease in a single centre using strict criteria for remission. Clinical Endocrinology 200256 541-551. (doi:10.1046/j.1365-2265. 2002.01511.x)

21 Bochicchio D, Losa M \& Buchfelder M. Factors influencing the immediate and late outcome of Cushing's disease treated by transsphenoidal surgery: a retrospective study by the European Cushing's Disease Survey Group. Journal of Clinical Endocrinology and Metabolism 199580 3114-3120. (doi:10.1210/jc.80.11.3114)

22 Chee GH, Mathias DB, James RA \& Kendall-Taylor P. Transsphenoidal pituitary surgery in Cushing's disease: can we predict outcome? Clinical Endocrinology 200154 617-626. (doi:10.1046/j.1365-2265.2001.01261.x) 
23 Guilhaume B, Bertagna X, Thomsen M, Bricaire C, Vila-Porcile E, Olivier L, Racadot J, Derome P, Laudat MH, Girard F et al. Transsphenoidal pituitary surgery for the treatment of Cushing's disease: results in 64 patients and long term follow-up studies. Journal of Clinical Endocrinology and Metabolism 198866 1056-1064. (doi:10.1210/jcem66-5-1056)

24 Blevins LS Jr, Christy JH, Khajavi M \& Tindall GT. Outcomes of therapy for Cushing's disease due to adrenocorticotropin-secreting pituitary macroadenomas. Journal of Clinical Endocrinology and Metabolism 1998 83 63-67. (doi:10.1210/jc.83.1.63)

25 Honegger J, Schmalisch K, Beuschlein F, Kaufmann S, Schnauder G, Naegele T \& Psaras T. Contemporary microsurgical concept for the treatment of Cushing's disease: endocrine outcome in 83 consecutive patients. Clinical Endocrinology 201276 560-567. (doi:10.1111/j.13652265.2011.04268.x)

26 Arnott RD, Pestell RG, McKelvie PA, Henderson JK, McNeill PM \& Alford FP. A critical evaluation of transsphenoidal pituitary surgery in the treatment of Cushing's disease: prediction of outcome. Acta Endocrinologica 1990123 423-430.

27 Bigos ST, Somma M, Rasio E, Eastman RC, Lanthier A, Johnston HH \& Hardy J. Cushing's disease: management by transsphenoidal pituitary microsurgery. Journal of Clinical Endocrinology and Metabolism 198050 348-354. (doi:10.1210/jcem-50-2-348)

28 Salassa RM, Laws ER Jr, Carpenter PC \& Northcutt RC. Transsphenoidal removal of pituitary microadenoma in Cushing's disease. Mayo Clinic Proceedings $1978 \mathbf{5 3} 24-28$.

29 Tahir AH \& Sheeler LR. Recurrent Cushing's disease after transsphenoidal surgery. Archives of Internal Medicine 1992152 977-981. (doi:10. 1001/archinte.1992.00400170067013)

30 Esposito F, Dusick JR, Cohan P, Moftakhar P, McArthur D, Wang C, Swerdloff RS \& Kelly DF. Clinical review: early morning cortisol levels as a predictor of remission after transsphenoidal surgery for Cushing's disease. Journal of Clinical Endocrinology and Metabolism 2006 91 7-13. (doi:10.1210/jc.2005-1204)

31 Lindsay JR, Oldfield EH, Stratakis CA \& Nieman LK. The postoperative basal cortisol and CRH tests for prediction of long-term remission from Cushing's disease after transsphenoidal surgery. Journal of Clinical Endocrinology and Metabolism 201196 2057-2064. (doi:10.1210/jc. 2011-0456)

32 Yap LB, Turner HE, Adams CB \& Wass JA. Undetectable postoperative cortisol does not always predict long-term remission in Cushing's disease: a single centre audit. Clinical Endocrinology 200256 25-31. (doi:10.1046/j.0300-0664.2001.01444.x)

33 Barber TM, Adams E, Ansorge O, Byrne JV, Karavitaki N \& Wass JA. Nelson's syndrome. European Journal of Endocrinology 2010163 495-507. (doi:10.1530/EJE-10-0466)
34 Hassan-Smith ZK, Sherlock M, Reulen RC, Arlt W, Ayuk J, Toogood AA, Cooper MS, Johnson AP \& Stewart PM. Outcome of Cushing's disease following transsphenoidal surgery in a single center over 20 years. Journal of Clinical Endocrinology and Metabolism 201297 1194-1201. (doi:10.1210/jc.2011-2957)

35 Dekkers OM, Biermasz NR, Pereira AM, Roelfsema F, van Aken MO, Voormolen JH \& Romijn JA. Mortality in patients treated for Cushing's disease is increased, compared with patients treated for nonfunctioning pituitary macroadenoma. Journal of Clinical Endocrinology and Metabolism 200792 976-981. (doi:10.1210/jc.20062112)

36 Cavagnini F \& Pecori Giraldi F. Epidemiology and follow-up of Cushing's disease. Annales d'Endocrinologie 200162 168-172. (doi:AE04-2001-62-2-0003-4266-101019-ART3)

37 Chen JC, Amar AP, Choi S, Singer P, Couldwell WT \& Weiss MH. Transsphenoidal microsurgical treatment of Cushing disease: postoperative assessment of surgical efficacy by application of an overnight low-dose dexamethasone suppression test. Journal of Neurosurgery 2003 98 967-973. (doi:10.3171/jns.2003.98.5.0967)

38 Flitsch J, Knappe UJ \& Ludecke DK. The use of postoperative ACTH levels as a marker for successful transsphenoidal microsurgery in Cushing's disease. Zentralblatt für Neurochirurgie 200364 6-11. (doi:10. 1055/s-2003-37145)

39 Pereira AM, van Aken MO, van Dulken H, Schutte PJ, Biermasz NR, Smit JW, Roelfsema F \& Romijn JA. Long-term predictive value of postsurgical cortisol concentrations for cure and risk of recurrence in Cushing's disease. Journal of Clinical Endocrinology and Metabolism 2003 88 5858-5864. (doi:10.1210/jc.2003-030751)

40 Hofmann BM \& Fahlbusch R. Treatment of Cushing's disease: a retrospective clinical study of the latest 100 cases. Frontiers of Hormone Research 200634 158-184. (doi:10.1159/000091580)

41 Rollin G, Ferreira NP \& Czepielewski MA. Prospective evaluation of transsphenoidal pituitary surgery in 108 patients with Cushing's disease. Arquivos Brasileiros de Endocrinologia e Metabologia 200751 1355-1361. (doi:10.1590/S0004-27302007000800022)

42 Prevedello DM, Pouratian N, Sherman J, Jane JA Jr, Vance ML, Lopes MB \& Laws ER Jr. Management of Cushing's disease: outcome in patients with microadenoma detected on pituitary magnetic resonance imaging. Journal of Neurosurgery 2008109 751-759. (doi:10.3171/JNS/ 2008/109/10/0751)

43 Alexandraki KI, Kaltsas GA, Isidori AM, Storr HL, Afshar F, Sabin I, Akker SA, Chew SL, Drake WM, Monson JP et al. Long-term remission and recurrence rates in Cushing's disease: predictive factors in a singlecentre study. European Journal of Endocrinology 2013168 639-648. (doi:10.1530/EJE-12-0921)

Received 1 August 2013

Revised version received 25 October 2013

Accepted 11 November 2013 